\title{
Arsenic species interactions with a porous carbon electrode as determined with an electrochemical quartz crystal microbalance
}

\author{
Emilia Morallón ${ }^{\mathrm{a}, *, 1}$, Joaquín Arias-Pardilla $^{\mathrm{a}}$, J.M. Calo $^{\mathrm{b}}$, D. Cazorla-Amorós ${ }^{\mathrm{c}}$ \\ a Departamento de Química Física and Instituto Universitario de Materiales, Universidad de Alicante, Apartado 99. 03080 Alicante, Spain \\ b Division of Engineering, Box D, Brown University, Providence, RI 02912, USA

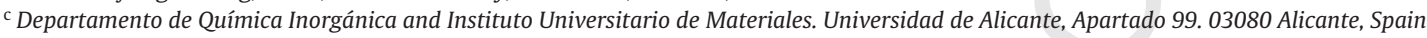

\section{A R T I C L E I N F O}

\section{Article history:}

Received 1 October 2008

Received in revised form 5 February 2009

Accepted 7 February 2009

Available online xxx

\section{Keywords:}

Arsenic species

Porous carbon electrode

Electrochemical quartz crystal

Anicrobalance

Electroadsorption

Ayclic voltammetry

\begin{abstract}
A B S T R A C T
The interactions of arsenic species with platinum and porous carbon electrodes were investigated with an electrochemical quartz crystal microbalance (EQCM) and cyclic voltammetry in alkaline solutions. It is shown that the redox reactions in arsenic-containing solutions, due to arsenic reduction/deposition, oxidation/desorption, and electrocatalyzed oxidation by Pt can be readily distinguished with the EQCM. This approach was used to show that the arsenic redox reactions on the carbon electrode are mechanistically similar to that on the bare Pt electrode. This could not be concluded with just classical cyclic voltammetry alone due to the obfuscation of the faradaic features by the large capacitative effects of the carbon double layer.

For the porous carbon electrode, a continual mass loss was always observed during potential cycling, with or without arsenic in the solution. This was attributed to electrogasification of the carbon. The apparent mass loss per cycle was observed to decrease with increasing arsenic concentration due to a net mass increase in adsorbed arsenic per cycle that increased with arsenic concentration, offsetting the carbon mass loss. Additional carbon adsorption sites involved in arsenic species interactions are created during electrogasification, thereby augmenting the net uptake of arsenic per cycle.

It is demonstrated that EQCM, and in particular the information given by the behavior of the time derivative of the mass vs. potential, or massogram, is very useful for distinguishing arsenic species interactions with carbon electrodes. It may also prove to be effective for investigating redox/adsorption/desorption behavior of other species in solution with carbon materials as well.
\end{abstract}

(C) 2009 Published by Elsevier Ltd.

\section{Introduction}

Although arsenic is not particularly abundant in the earth's crust, it is a widely distributed element that is highly toxic (i.e., as inorganic As(III)) [1,2]. These properties and the solubility and reactivity of arsenic compounds, make leaching and pollution of natural waters by arsenic a matter of worldwide concern. This situation has provoked significant research activity directed at the development of speciation and detection methods, and of efficient removal techniques.

Speciation and quantification of arsenic are difficult because the concentrations of interest in water are typically at $\mu \mathrm{g} / \mathrm{L}$ levels, which are of the same order of magnitude as the detection limits of many of the most relevant techniques [3]. Among these techniques, electrochemical methods can be useful for both speciation and detection of arsenic at $\mu \mathrm{g} / \mathrm{L}$ levels $[1,2,4]$.

\footnotetext{
* Corresponding author. Tel.: +34 65909590; fax: +34 965903537

E-mail address: morallon@ua.es (E. Morallón).

${ }^{1}$ ISE Member.
}

The removal of arsenic species can be accomplished via various methods, including adsorption, precipitation, coagulation, and membrane separation [5,6]. In most of these methods, the efficiency towards As(III) removal is significantly less than for $\mathrm{As}(\mathrm{V})$, which makes it necessary to increase the $\mathrm{pH}$ of the solution to pre-oxidize As(III) species. In the case of adsorption, however, apparently both $\mathrm{As}(\mathrm{III})$ and $\mathrm{As}(\mathrm{V})$ can be removed under appropriate conditions [6].

Recently, electrosorption on porous carbons has been proposed as a possible technique for arsenic removal from water [7]. Adsorption from solution by activated carbons is strongly dependent on the chemical nature of the adsorptive (i.e., molecular structure, size, charge, etc.), the $\mathrm{pH}$ of the solution, ionic strength, porosity and surface chemistry of the carbon material [8]. Thus, the surface charge of the porous carbon relative to that of the adsorptive can have a strong influence on the adsorption process. In these cases, the adsorption properties of the porous carbon may be modified via the application of an electric potential, and the adsorption or desorption of charged species may be achieved by changing the polarity of the applied potential [7]. This type of experiment has been performed with arsenic species in solution at conditions similar to those in natural waters with positive results [7]. 
The preceding motivated our interest in exploring the electrochemical behavior of arsenic species in porous carbon electrodes. However, the application of conventional electrochemical techniques, like cyclic voltammetry, to porous carbons is complicated by the characteristically large contribution of the double layer charge of these materials. This impedes the direct observation of faradaic processes, especially at low concentrations. A complementary approach used in the current work to help circumvent this problem, is the application of an electrochemical quartz crystal microbalance (EQCM) to monitor changes of the electrode mass with ng sensitivity, in addition to the detection of charge-transfer reactions as with conventional electrochemical techniques. The objective of the current study is to investigate the electrochemical behavior of arsenic species with a porous carbon through the use of the EQCM.

\section{Experimental}

\subsection{Materials}

A powdered commercial activated carbon was selected (carbon black T-10157 from Cabot Corp.) to serve as an electrode. The porous texture of this carbon was characterized by gas adsorption $\left(\mathrm{N}_{2} @ 77 \mathrm{~K}\right.$ and $\mathrm{CO}_{2} @ 273 \mathrm{~K}$ ) with an Autosorb-6 apparatus (Quantachrome Corp.). The $\mathrm{N}_{2}$ adsorption isotherms for this carbon are type I, although with a wide knee (i.e., wide micropore size distribution), and a positive slope at relative pressures greater than 0.2 , which is indicative of the presence of mesoporosity. Specific surface area and micropore volumes were calculated by fitting $\mathrm{N}_{2}$ adsorption data to the BET and Dubinin-Radushkevich equations, respectively, resulting in $\mathrm{S}_{\mathrm{BET}}=1650 \mathrm{~m}^{2} \mathrm{~g}^{-1}$, and $\mathrm{V}_{\mathrm{DR}}\left(\mathrm{N}_{2}\right)=0.66 \mathrm{~cm}^{3} \mathrm{~g} \mathrm{~g}^{-1}$. The volume of narrow micropores was obtained by fitting the Dubinin-Radushkevich equation to the $\mathrm{CO}_{2}$ isotherm data, which gave $\mathrm{V}_{\mathrm{DR}}\left(\mathrm{CO}_{2}\right)=0.41 \mathrm{~cm}^{3} \mathrm{~g}^{-1}$.

The charge of the carbon surface during adsorption is determined by the $\mathrm{pH}$ of the solution. The carbon surface charge will be positive at a solution $\mathrm{pH}$ less than its point of zero charge ( $\mathrm{pH}$ PZC), and will be negative at a solution $\mathrm{pH}$ greater than $\mathrm{pH}_{\mathrm{PZC}}$. The $\mathrm{pH}_{\mathrm{PZC}}$ was determined using a modified version of the method proposed by Noh et al. [9] from suspensions of increasing amounts of carbon material $(0.05,0.1,0.5,1,5$ and $10 \mathrm{wt} \%)$ in ultrapure water. The samples were left to attain equilibrium in an agitated thermostatic bath for $24 \mathrm{~h}$ at $25^{\circ} \mathrm{C}$. After filtration, the final $\mathrm{pH}$ of the suspensions was measured and the $\mathrm{pH}_{\mathrm{PzC}}$ was determined from the asymptotic tendency of the $\mathrm{pH}$ values of the different suspensions. The $\mathrm{pH}_{\mathrm{PZC}}$ determined in this manner was 7.1.

The arsenic solutions were made by diluting an arsenic standard ( $1 \mathrm{mg} / \mathrm{mL}$ As in $2 \% \mathrm{KOH}$ from Aldrich) with $0.02 \mathrm{M} \mathrm{NaCl}$ solution. Different concentrations of arsenic, from 25 to $100 \mathrm{ppm}$, were prepared in this manner. Under these conditions (i.e., at pH values from 12 to 12.5$)$, most of the arsenic is present as $\mathrm{AsO}_{4}{ }^{3} \wedge(>95 \%)$, and a small amount as $\mathrm{HAsO}_{4}{ }^{2} \wedge(<5 \%)$ (as determined with CHEAQS [10]).

\subsection{EQCM measurements}

The electrodes used for the EQCM measurements were AT-cut $9 \mathrm{MHz}$ piezoelectric quartz crystals, coated with Pt $(0.3 \mu \mathrm{m}$ thick) deposited over a Ti adhesion layer ( $50 \mathrm{~nm}$ thick), with an area of $0.196 \mathrm{~cm}^{2}$. The surface roughness of the electrode was determined to be 2.1 from the reduction peak B in Fig. 1 (see below). The quartz crystal was set vertically in a cell made of Teflon and used as the working electrode in a three-electrode electrochemical cell. The reference electrode was $\mathrm{Ag} / \mathrm{AgCl}$ (Satd $\mathrm{KCl}$ ), and a spiral-wound platinum wire was used as the counter-electrode. The electrochemical experiments were performed with an EG\&G

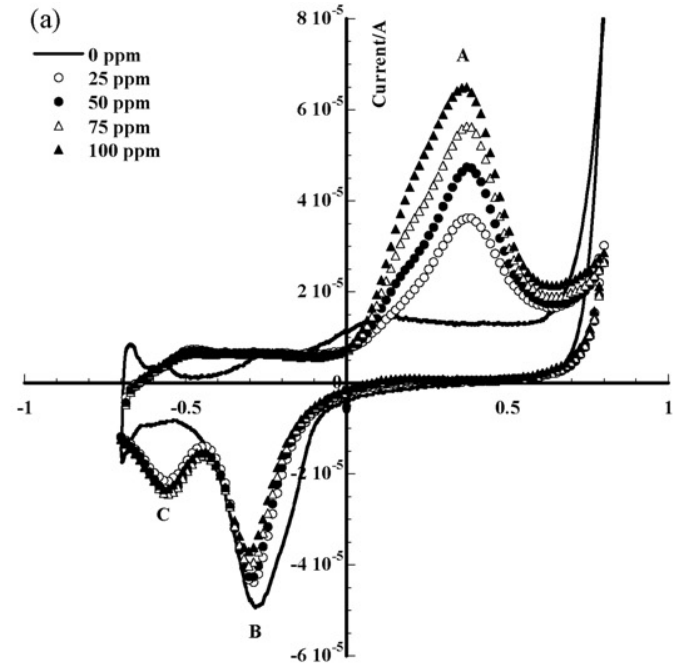

Potential/V (Ag/AgCl)

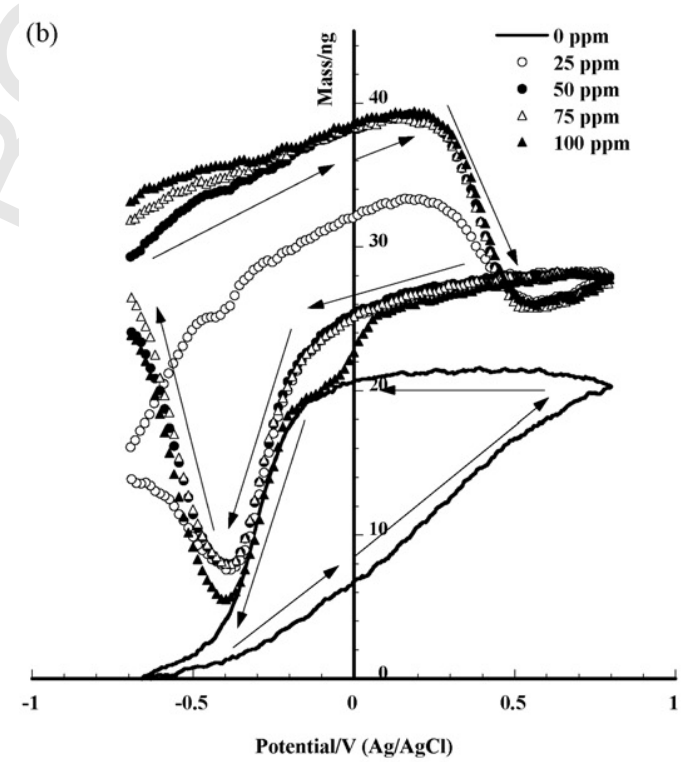

(c)

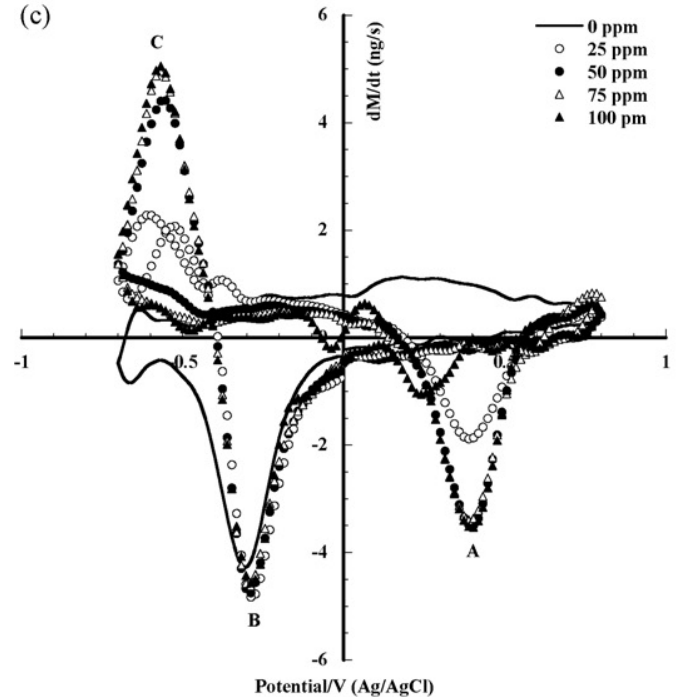

Fig. 1. (a) Voltammogram; (b) electrode mass behavior; and (c) massogram $m_{\triangle}(\mathrm{d} M / \mathrm{d} t$ vs. E) of the bare Pt electrode at a solution $\mathrm{pH}$ of 12 at $50 \mathrm{mV} / \mathrm{s}$ in $\mathrm{NaCl}$ electrolyte, as Afunction of arsenic concentration. The data all correspond to the fifth voltammetric cycle beginning with a positive potential sweep from $0 \mathrm{~V}$, except for the anodic sweep portion from -0.7 to $0 \mathrm{~V}$, which is the end of the fourth cycle. 
PAR model 263A potentiostat. The EQCM was an EG\&G PAR model QCA917. A capacitance of $1 \mathrm{nF}$ was used to isolate the potentiostat from the microbalance. The resonant frequency and the resonant admittance were converted into an analog voltage with a digitalto-analog converter and recorded. Linearity of the relation between resonance frequency and the change in crystal mass was verified by platinum electrodeposition and the Sauerbrey equation:

$\Delta f=\frac{-2 n f^{2}}{\sqrt{\mu_{\mathrm{Q}} \rho_{\mathrm{Q}}}} \frac{\Delta m}{A}$

where $\Delta f$ is the measured resonant frequency change $(\mathrm{Hz}), n$ is the fundamental mode of the crystal, $f^{2}$ is the resonant frequency prior to deposition, $\mu_{\mathrm{Q}}$ is the shear modulus of quartz

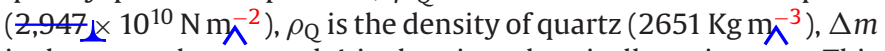
is the mass change, and $A$ is the piezoelectrically active area. This equation was used to calculate the mass change from the frequency change, neglecting the small viscous effects observed, with an integral sensitivity of $1.7 \times 10^{8} \mathrm{~Hz} \mathrm{~cm}^{-2} \mathrm{~g}^{-1}$.

Cabot carbon black T-10157 was mixed with Teflon binder (20 wt\%) and then with water to make an emulsion of $25 \mathrm{mg}$ carbon $/ \mathrm{ml}$. This mixture was homogenized in an ultrasonic bath for at least $40 \mathrm{~min}$. $10 \mu \mathrm{L}$ of this emulsion was deposited on the platinum electrode and dried with an IR lamp. All measurements were performed under ambient conditions. The amount of deposited activated carbon was about $250 \mu \mathrm{g}$. However, the frequency change detected corresponds only to about $1 \mu \mathrm{g}$. The change in frequency was less than $2 \%$ of the frequency of the unloaded crystal, and thus use of the Sauerbrey equation is warranted [11]. In this case the sensitivity, as determined by platinum electrodeposition, is of the same order of magnitude as that with platinum electrode. The surface roughness of the electrode is around 80. At high rugosity values such as this, the measured frequency changes could be affected via the opposing effects of mass increase and rugosity reduction $[12,13]$. However, in the current case, the quantities of arsenic deposited are so low (on the order of ng) that no significant change in rugosity will occur.

\section{Results and discussion}

\subsection{Response of the Pt electrode}

In Fig. 1 are presented data obtained during a steady voltammetric cycle for the EQCM bare Pt electrode: (a) the $\mathrm{CV}$ data at $50 \mathrm{mV} / \mathrm{s}$; (b) the corresponding EQCM mass data; and (c) the derivative of the EQCM mass data, or the massogram [14]. Each voltammetric cycle begins at $0 \mathrm{~V}$, ramps anodically to $+0.8 \mathrm{~V}$, then cathodically from +0.8 to $-0.7 \mathrm{~V}$, and then completes the cycle anodically from -0.7 to $0 \mathrm{~V}$. The data shown are for the fifth cycle, except for the anodic portion from -0.7 to $0 \mathrm{~V}$, which is the end of the fourth cycle. (The voltammograms are steady by about the third cycle.) Fig. $1 a$ and $b$ is discussed immediately below, and Fig. 1c subsequently.

As shown in Fig. 1a, without arsenic the voltammogram exhibits the characteristic features expected for a platinum electrode. The region between -0.7 and $-0.55 \mathrm{~V}$ corresponds to the so-called hydrogen adsorption-desorption zone. During the anodic sweep, $\mathrm{OH}^{-}$adsorption is first observed at about $-0.26 \mathrm{~V}$, beginning the formation of platinum surface oxide. During the cathodic sweep, the reduction peak $(B)$ of the platinum surface oxides, located at about $-0.28 \mathrm{~V}$, is also observed $[15,16]$. It is noted that all the potentials reported here are vs. $\mathrm{Ag} / \mathrm{AgCl}(\mathrm{Satd} \mathrm{KCl})$, and they are shifted to significantly lower values than in acidic media, in accordance with the well-known dependence of reaction potential on $\mathrm{pH}$.

As shown in Fig. 1a, the addition of arsenic results in the appearance of a large peak (A) in the steady voltammograms, located at about $+0.38 \mathrm{~V}$, and another cathodic peak (C) located at about $\Lambda^{-0.56} \mathrm{~V}$. Peak A has been attributed to the catalytic oxidation of
$\mathrm{As}(\mathrm{III})$ to $\mathrm{As}(\mathrm{V})$ on Pt by a number of authors [3,17-20]. Cabelka et al. [17] observed this peak in an acidic medium at $+0.85 \mathrm{~V}$ (vs. SCE) and attributed it "to the simultaneous processes of (i) oxide formation, (ii) oxidation of adsorbed As(III), and (iii) oxidation of As(III) transported to the electrode surface..." The data in Fig. 1a exhibit a linear increase in the peak current of peak $\mathrm{A}$ of $0.15 \mathrm{~A} / \mathrm{em}^{2}$ $(\mathrm{M} \mathrm{As})^{-1}$, while the data of Cabelka et al. [17] in an acidic medium on a Pt RDE also show a linear, but larger current increase of about $1.3 \mathrm{~A}_{\mathrm{em}} \mathrm{A}^{-2}(\mathrm{M} \mathrm{As})^{-1}$. The data of Dai and Compton [3], also in an acidic medium on a Pt "macro electrode," exhibit the same behavior, but with $0.6 \mathrm{~A} / \mathrm{em}^{-2}(\mathrm{M} \mathrm{As})^{-1}$. These observed differences are attributed to the available amount of As(III) in acidic vs. alkaline media, and/or perhaps the number of catalytic Pt sites available for arsenic oxidation from solution in the case of each electrode. In alkaline solutions, almost all the arsenic in the bulk solution is $\mathrm{As}(\mathrm{V})$. Consequently, the contribution of $\mathrm{As}(\mathrm{III})$ from solution to the oxidation peak is limited to what is formed and present on the surface and available in solution in the vicinity of the surface during the CV. Peak C in Fig. 1a is attributed to the formation of $\mathrm{As}(0) / \mathrm{As}(\mathrm{III})$ on the Pt surface [17]. The anodic current observed from -0.5 to $0 \mathrm{~V}$ during the anodic sweep is attributed to the oxidation of $\operatorname{As}(0)$ as subsequently discussed below.

In Fig. 1b are presented the corresponding mass data for the $\mathrm{Pt}$ electrode vs. the potential, as recorded by the EQCM for the same cycle as in Fig. 1a. As shown, the data without arsenic exhibit completely reversible mass gain and loss and zero net change in mass per cycle. Most of the mass is gained relatively evenly during the anodic sweep, corresponding to platinum oxidation, and most of it is lost more precipitously in the reduction of platinum oxides during the cathodic sweep. The mass data with arsenic in solution are quite different. Almost all of the mass gain occurs at the end of the cathodic sweep, which coincides with the reduction peak attributed primarily to the formation of $\mathrm{As}(0) / \mathrm{As}(\mathrm{III})$ (peak C). The mass loss occurs in two stages-during the anodic sweep at positive potentials (peak A) from approximately $0.3 \mathrm{~V}$, and another coincident with the negative cathodic peak (peak B), which is attributed primarily to the reduction of the Pt surface.

From Fig. 1b, the mass loss over peak A during the anodic sweep from about $0 \widehat{V}$ to the end of the sweep is the same value of about $10.5 \mathrm{ng}$ for 100,75 , and $50 \mathrm{ppm}$ solutions. (The $25 \mathrm{ppm}$ solution data are discussed further below). However, it is also noted that the electrode mass in the absence of arsenic increases by about 13.5 ng over this same potential range due to Pt oxidation. Consequently, the latter behavior considerably "masks" the actual mass loss due to arsenic oxidation/desorption. During the anodic sweep over the potential region of peak $\mathrm{A}$ it is quite likely that almost all the active Pt sites, whether originally containing adsorbed arsenic or not, end up oxidized by the end of the sweep (as evidenced by the relatively flat mass curve during the return cathodic sweep for Pt in the absence of arsenic), then it is reasonable to assume that the total mass gain due to Pt oxidation will be roughly similar in the presence of arsenic as well. This assumption means that the actual mass loss due to oxidation/desorption of adsorbed arsenic for the three highest concentration arsenic solutions was actually about $24 \mathrm{ng}$. This approximation is supported by the behavior of the "loop" in the mass record evident at the highest anodic potentials for all the arsenic-containing solutions upon switching from the anodic to the cathodic sweep, which is invariant with arsenic concentration. Examination of these data indicates that this "loop" is caused by the mass increase due to Pt oxidation, occurring simultaneously with the mass loss due to oxidation/desorption of arsenic from the surface. Correction of the mass behavior due to Pt oxidation eliminates this "loop" for all the arsenic solutions, consistent with the preceding assumption.

Shibata et al. [19] have determined that arsenic deposited as $\mathrm{As}(0)$ under cathodic conditions (in peak $\mathrm{C}$ ) becomes oxidized to 
$\mathrm{As}(\mathrm{III})$ as $\left(\mathrm{As}_{2 \mathrm{n}}\right)_{(\mathrm{ad})} \mathrm{O}_{3 \mathrm{n}}$ complexes on Pt and $\mathrm{Au}$ surfaces, where the $\mathrm{As}_{\mathrm{ad}}$ are adsorbed arsenic atoms, or "ad-atoms." The subsequent oxidation/hydrolysis/desorption of these complexes to $\mathrm{As}(\mathrm{V})$ in alkaline solution occurs according to the stoichiometry:

$\left(\mathrm{As}_{2}\right)_{(\mathrm{ad})} \mathrm{O}_{3}+10 \mathrm{OH}{ }^{-} \rightarrow 2 \mathrm{AsO}_{4}{ }^{3-}+5 \mathrm{H}_{2} \mathrm{O}+4 \mathrm{e}$,

which corresponds to a net mass loss from the electrode of $99 \mathrm{~g} / \mathrm{mol}$ $\mathrm{As}_{\mathrm{ad}}$.

Since the mass loss in peak $A$ is the same for the three highest arsenic concentrations, this means that the adsorbed arsenic sites at the inception of peak A are saturated for the three highest concentrations (but not for the lowest concentration of $25 \mathrm{ppm}$, from which only a net mass loss of about 17 ng occurs). However, as can be seen from Fig. 1a, the total charge comprising the peak increases monotonically with arsenic concentration. Consequently, there must be an additional process occurring than the oxidation of just the adsorbed arsenic to produce the significant observed change in current.

It has been well established that Pt sites can participate catalytically in the oxidation of As(III) from solution in accordance with a process that has been demonstrated for arsenic in acidic solutions $[3,17,18]$. In this process, $\mathrm{OH}^{-}$and $\mathrm{As}(\mathrm{III})$ are adsorbed on a Pt site from solution. Transfer of the oxygen atom from the adsorbed $\mathrm{OH}$ to arsenic then oxidizes $\mathrm{As}(\mathrm{III})$ to $\mathrm{As}(\mathrm{V})$, which then desorbs from the catalytic site to complete the process. In alkaline solution at elevated $\mathrm{pH}, \mathrm{As}(\mathrm{O})_{2} \mathrm{OH}^{2}-(\mathrm{aq})$ is the most stable form of $\mathrm{As}(\mathrm{III})[21,22]$, and the corresponding anodic electrocatalytic process is:

$\mathrm{As}(\mathrm{O})_{2} \mathrm{OH}^{2-}(\mathrm{aq})+3 \mathrm{OH}^{-} \rightarrow \mathrm{AsO}_{4}{ }^{3-}(\mathrm{aq})+2 \mathrm{H}_{2} \mathrm{O}+2 \mathrm{e}$

with no attendant change in the electrode mass.

From the preceding, it is concluded the peak A current is the result of at least two processes: (1) oxidation of $\left(\mathrm{As}_{2 \mathrm{n}}\right)_{\mathrm{ad}} \mathrm{O}_{3 \mathrm{n}}$ surface complexes that originate from the reduction of $\mathrm{As}(\mathrm{V})$ from solution in peak C; and (2) electrocatalytic oxidation of As(III) from solution in the immediate vicinity of the electrode.

In Table 1 are summarized the results obtained from the analysis of peak $\mathrm{A}$, in accordance with the preceding observations. It is noted that the total charge in peak A (corrected for the double layer charge) is almost perfectly linear with the bulk As concentration at $0.025 \mathrm{nmol}$ electrons $/ \mathrm{ppm}$ As. As shown, the contribution to the total charge from the oxidation/desorption of the pre-existing As(III) surface complexes produced by $\operatorname{As}(0)$ oxidation is less than that from the electrocatalytic oxidation of As(III) from solution, ranging from about $27 \%$ for the $25 \mathrm{ppm}$ solution to $15 \%$ of the total for the $100 \mathrm{ppm}$ solution. In the case of the $25 \mathrm{ppm}$ solution, it is apparent that there was insufficient arsenic deposited on the Pt electrode prior to peak A to populate all the available contiguous sites, as occurred for the three higher concentrations. However, as shown in Table 1, the amount of As(III) oxidized from solution remains linear in the bulk arsenic concentration.
The amount of Pt active sites calculated from the total corrected charge in reduction peak $\mathrm{B}$ for the non-arsenic-containing electrolyte in Fig. 1a is 0.9 nmol. Based on this value, from Table 1 it is noted that the "Pt-catalyzed" oxidation of $\mathrm{As}(\mathrm{III})$ to $\mathrm{As}(\mathrm{V})$ becomes truly catalytic (i.e., exhibiting a turnover number greater than unity) for the two highest As concentrations of 75 and $100 \mathrm{ppm}$.

Under alkaline conditions, practically all the arsenic in the bulk solution is $\mathrm{As}(\mathrm{V})$. Consequently, the contribution of $\mathrm{As}(\mathrm{III})$ from solution to the oxidation peak is limited to what is available in the immediate vicinity of the surface during the CV. In Fig. 1b, at the inception of the return cathodic sweep following peak A, it is noted that the mass of the electrode following peak A continues to decrease slowly. (The mass loss is also "masked" by the increase in mass of the Pt electrode over in this region.) Thus, there is still some arsenic left on the electrode after peak A.

It is well known that stable Pt oxides "passivate" the Pt surface with respect to "detection," or oxidation of As(III) [18]. Cabelka et al. [17] have postulated As(III) adsorption onto PtO, as well as $\mathrm{PtOH}$ sites. Those adsorbed on PtO sites will be stable, since the oxygen atom is bonded to Pt and will not oxidize As(III). These PtOAs(III) complexes will survive anodic oxidation until Pt is reduced. The latter begins at about $-0.1 \mathrm{~V}$ to become peak B (i.e., "peak D" in the work of Cabelka et al. [17]). As shown in Fig. 1a, in the presence of arsenic the amplitude of this peak decreases and shifts to more negative potentials with increasing arsenic concentration. This process occurs simultaneously with the reduction of Pt surface oxides (peak B). In the vicinity of peak B it is expected that the $\mathrm{PtO}$ in the stable arsenic sites will also be reduced; e.g., in alkaline solution:

$\mathrm{e}+\mathrm{H}_{2} \mathrm{O}+\operatorname{PtOAs}_{(\mathrm{ad})}(\mathrm{O})_{2} \mathrm{OH}^{2} \AA \rightarrow \operatorname{PtOHAs}_{(\mathrm{ad})}(\mathrm{O})_{2} \mathrm{OH}^{2} \AA+\mathrm{OH}^{-}$

The oxygen atom in the adsorbed $\mathrm{OH}$ in $\mathrm{PtOH}$ sites has been identified as primarily responsible for the oxidation of As(III) from solution to $\mathrm{As}(\mathrm{V})$ in anodic peak A $[3,17,19]$. Consequently, As(III) in the resultant complex can then be oxidized by transfer of the oxygen from the adsorbed $\mathrm{OH}$ to arsenic:

$\operatorname{PtOHAs}_{(\mathrm{ad})}(\mathrm{O})_{2} \mathrm{OH}^{2} \bar{\Lambda}+2 \mathrm{OH}^{-} \rightarrow \mathrm{PtAs}_{(\mathrm{ad})}(\mathrm{O})_{4}{ }^{3-}+2 \mathrm{H}_{2} \mathrm{O}+\mathrm{e}$

In the total current data in Fig. 1a, reactions (4 and 5) represent a redox process (i.e., Pt reduction and arsenic oxidation) that produces no net charge. Consequently, it appears as an "inhibition" or diminution of peak B in terms of total current, since the Pt sites involved do not consume an electron as they would have in the absence of the stable arsenic complexes.

In Fig. 1a it is noted that there is almost zero anodic current for all the arsenic solutions during the return cathodic sweep from about 0.7 to $0.1 \mathrm{~V}$. However, the data of Cabelka et al. [17] and Dai and Compton [3] in acidic media, both exhibit considerable anodic current over this range of potential, proportional to the bulk concentration of arsenic in their solutions. Under acidic conditions, where $\mathrm{As}(\mathrm{III})$ is the predominant arsenic form in the bulk solution,

Table 1

Results of the analysis of peak A.

\begin{tabular}{|c|c|c|c|c|c|}
\hline $\begin{array}{l}\text { Arsenic solution } \\
\text { concentration (ppm) }\end{array}$ & $\begin{array}{l}\text { Total anodic charge } \\
\text { (a) (Inthol electrons) }\end{array}$ & $\begin{array}{l}\text { Mass loss } \\
\text { (b) (n̂mol) }\end{array}$ & $\begin{array}{l}\text { Anodic charge due to mass } \\
\text { loss (c) (hmol electrons) }\end{array}$ & $\begin{array}{l}\text { Anodic charge due to As(III) } \\
\text { adsorption/oxidation from } \\
\text { solution (d) (nmol electrons) }\end{array}$ & $\begin{array}{l}\text { As(III) from solution oxidized } \\
\text { on Pt Sites (e) (nmol) }\end{array}$ \\
\hline 25 & 1.35 & 0.18 & 0.36 & 0.99 & 0.50 \\
\hline 50 & 1.96 & 0.24 & 0.48 & 1.48 & 0.74 \\
\hline 75 & 2.58 & 0.24 & 0.48 & 2.10 & 1.05 \\
\hline 100 & 3.20 & 0.24 & 0.48 & 2.72 & 1.36 \\
\hline
\end{tabular}

(a) Integral of peak A current $(50 \mathrm{mV} / \mathrm{s}$ ), corrected for the electrode double layer charge.

(b) Assuming $99 \mathrm{~g} / \mathrm{mol}$ mass loss (reaction (2)).

(c) 2 electrons per original $\mathrm{As}_{\mathrm{ad}}$ oxidized/desorbed (reaction (2)).

(d) By difference.

(e) 2 electrons per As(III) oxidized from solution (reaction (3)). 
the anodic current during the return cathodic sweep is most probably a continuation of the electrocatalytic oxidation of As(III) from solution. However, in the present case under alkaline conditions, where all the available As(III) in solution in the immediate vicinity of the electrode appears to be exhausted in peak A, there should be little or no anodic current over this same potential range, just as shown by the data.

Immediately following peak B in the cathodic sweep appears peak $C$, that is attributed to the adsorption and reduction of $\mathrm{As}(\mathrm{V})$ from solution. Since the potential stability region for As(III) at high $\mathrm{pH}$ is very narrow $[21,22]$, the reduction of $\mathrm{As}(\mathrm{V})$ to $\mathrm{As}(\mathrm{III})$ will be immediately followed by reduction to $\operatorname{As}(0)$, resulting in elemental arsenic deposition, contributing to the observed precipitous mass increase over a small potential range (Fig. 1b). This is the primary source of the arsenic that is subsequently oxidized back to $\mathrm{As}(\mathrm{V})$ and desorbed in peak A. Once deposited, the $A s(0)$ undergoes rapid oxidation to form an "oxy-arsenic surface polymer" of As(III) with a planar structure [19]. As discussed above, Shibata et al. [19] proposed that $\mathrm{As}_{(\mathrm{ad})}(0)$ ad-atoms are deposited on the Pt surface by rapid reduction of $\mathrm{As}(\mathrm{V})$ from solution. $\mathrm{As}_{(\mathrm{ad})}(0)$ is then oxidized to $\mathrm{a}+1$ valence state, $\mathrm{OH}-\mathrm{As}_{(\mathrm{ad})}$, and then rapidly to $\mathrm{As}_{(\mathrm{ad})}(\mathrm{III})$, forming $\mathrm{As}_{2 \mathrm{n}} \mathrm{O}_{3 \mathrm{n}}$. The initial mechanistic step proposed by Shibata et al. [19] exhibits a mass change per electron, $M / n=17$. Subsequent steps in their mechanism to produce $\mathrm{As}_{(\mathrm{ad}) 2 \mathrm{n}} \mathrm{O}_{3 n}$ exhibit $M / n=8$. It is noted, however, that their data are also consistent with the electrocatalytic mechanism discussed above. That is, in alkaline media, $\mathrm{OH}^{-}$adsorbs onto $\mathrm{As}(0)$ sites:

$\mathrm{OH}^{-}+\mathrm{Pt}\left[\operatorname{As}_{(\mathrm{ad})}(0)\right] \rightarrow \operatorname{PtOH}\left[\mathrm{As}_{(\mathrm{ad})}(0)\right]+\mathrm{e}$,

with $M / n=17$. Subsequent transfer of the oxygen atom from the adsorbed $\mathrm{OH}$ to arsenic will then oxidize $\mathrm{As}(0)$ to $\mathrm{As}(\mathrm{III})$ :

$2 \mathrm{OH}^{-}+\mathrm{PtOH}\left[\mathrm{As}_{(\mathrm{ad})}(0)\right] \rightarrow \mathrm{Pt}\left[\mathrm{OAs}_{(\mathrm{ad})}(\mathrm{III}) \mathrm{OH}\right]+\mathrm{H}_{2} \mathrm{O}+2 \mathrm{e}$,

with $M / n=8$. Condensation reactions between contiguous oxidized arsenic sites will then produce $\mathrm{As}_{(\mathrm{ad}) 2} \mathrm{O}_{3}$ :

$$
\begin{aligned}
& \mathrm{Pt}\left[\mathrm{OAs}_{(\mathrm{ad})}(\mathrm{III}) \mathrm{OH}\right]+\mathrm{Pt}\left[\mathrm{OAs} s_{(\mathrm{ad})}(\mathrm{III}) \mathrm{OH}\right] \\
& \quad \rightarrow \mathrm{Pt}\left[\mathrm{O}=\mathrm{As}_{(\mathrm{ad})}(\mathrm{III})-\mathrm{O}-\mathrm{As}_{(\mathrm{ad})}(\mathrm{III})=\mathrm{O}\right] \mathrm{Pt}+\mathrm{H}_{2} \mathrm{O},
\end{aligned}
$$

etc., to continue to grow the surface oxide as $\mathrm{As}_{(\mathrm{ad}) 2 \mathrm{n}} \mathrm{O}_{3 \mathrm{n}}$. In alkaline media, the overall stoichiometry is:

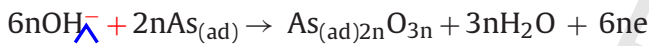

with $M / n=8$. From the current data and that which exists in the literature, it is not possible to determine which mechanism is more correct-that of Shibata et al. [19] involving arsenic oxidation to a + 1 vâlence state, or the electrocatalytic oxygen transfer reaction. However, this mechanistic difference does not affect the present data analysis and conclusions.

The apparent mass gain in peak $C$ for the three highest concentration arsenic solutions is about the same at $18.4 \mathrm{ng}$. However, from Fig. 1b it is noted that the Pt electrode in the absence of arsenic loses about $4.3 \mathrm{ng}$ over the same potential range, which "masks" the actual mass gain due to arsenic. If it is assumed that the latter remains about the same in the presence of arsenic, this means that approximately $22.7 \mathrm{ng}$ is gained from arsenic deposition. The charge, corrected, for the double layer charge over this same range, is about 0.71 electron $\mathrm{nmol}$, or $M / n=32 \mathrm{~g} /$ electron mol. The process of adsorption and reduction of $\mathrm{As}(\mathrm{V})\left(\mathrm{as} \mathrm{AsO}_{4}{ }^{3} \mathrm{~A}\right)$ from solution to As( 0 ) yields $M / n=75 / 5=15 \mathrm{~g} /$ electron mol, while the overall process of adsorption and reduction of $\mathrm{As}(\mathrm{V})$ to adsorbed $\mathrm{As}$ (III) (as $\mathrm{AsO}_{1.5}$ ) is $99 / 2=49.5 \mathrm{~g} /$ electron mol. Since the experimental value lies between these two limits, it is concluded that about $76 \%$ of the $\mathrm{As}(\mathrm{V})$ from solution is reduced to $\mathrm{AsO}_{1.5}$ in peak $\mathrm{C}$. The remaining $24 \%$ of the arsenic as $\operatorname{As}(0)$ becomes oxidized during the return anodic sweep following peak $\mathrm{C}$, which gives rise to the anodic current during the anodic sweep from about -0.5 to $0 \mathrm{~V}$, and the

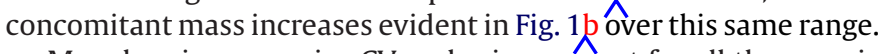

Mass loss in successive CV cycles is apparent for all the arsenic solutions at the lowest potentials, which repeats from cycle to cycle after the voltammograms become steady (i.e., after about the third cycle). From Fig. 1b, these mass "deficits" are about 2.3, 4.9, 5.4, and $8.8 \mathrm{ng}$ for the $25,50,75$, and $100 \mathrm{ppm}$ solutions. Since no corresponding mass deficit occurs in the absence of arsenic, these must be due to arsenic redox processes. The mass increase due to arsenic reduction in peak $C$ is roughly the same as the mass loss due to oxidation in peak A. However, the mass remaining on the electrode following peak $A$ is of the same order of magnitude as the mass deficit between cycles. As discussed above, the arsenic mass remaining on the electrode at the end of peak $A$ is attributed to stable As(III) complexes formed from solution on deactivated PtO sites that are slowly oxidized and desorb as $\mathrm{As}(\mathrm{V})$ during the return cathodic sweep following peak A.

In Fig. 1c is presented a plot of the derivative of the electrode mass with respect to time ( $\mathrm{d} M / \mathrm{d} t)$ vs. the applied potential, known as a massogram [14,23-25]. This type of data representation can be particularly useful in cases where the current behavior is coupled to adsorption/desorption of species, and where capacitative current effects predominate such that the CV is relatively featureless, as is the case with arsenic redox on the carbon electrode (CE) (see below). In the absence of arsenic, Fig. 1c clearly shows the large mass loss peak during the cathodic sweep, corresponding to the reduction of Pt surface oxides (peak B) $[3,17,18]$. It also shows the more gradual and steady mass gain during the anodic sweep due to platinum oxidation. In the presence of arsenic, the maximum of the cathodic mass loss corresponding to reduction of platinum surface oxides (peak B) appears to shift slightly to more positive potentials, similar to what is evident in the behavior of the charge in Fig. 1a. Fig. 1c also clearly shows the anodic mass loss peak (peak A) and the cathodic mass gain peak (peak C).

\subsection{EQCM response of the carbon electrode (CE) in the electrolyte}

In Fig. 2a are presented cyclic voltammograms (CV) for the carbon electrode (CE) in the sodium chloride electrolyte for five consecutive cycles, starting from $0 \mathrm{~V}$. As shown, in comparison to Fig. 1a, the CV is featureless, reflecting an essentially capacitative process, in agreement with the large contribution of the double layer to the total charge. This also indicates that the process is dominated by the $\mathrm{CE}$, and that the effects of the underlying Pt surface are negligible in the presence of the carbon layer.

In Fig. 2b are presented the corresponding mass data for the CE vs. potential, as recorded with the EQCM for five consecutive cycles. As shown, the CE mass decreases continuously, but steadily, with cycling by about $14-18 \mathrm{ng} /$ cycle. Once steady cyclic conditions are attained, the largest mass loss occurs during the cathodic sweep from $0 \mathrm{~V}$ to more negative potentials. This is followed by a smaller mass increase during the anodic sweep. Experiments were also conducted continuously under similar conditions for up to 30 cycles, while exhibiting very similar steady mass losses. This behavior differs significantly from that in Fig. 1b in the absence of arsenic for the bare Pt electrode, for which the mass record was completely reversible and reproducible from cycle to cycle. Consequently, the behavior in Fig. 2b must be due to a net mass loss of carbon from redox processes under these experimental conditions. Similar redox processes have also been observed during the investigation of capacitance changes with $\mathrm{pH}$ of a high specific surface area carbon cloth [26]. Under alkaline conditions ( $\mathrm{pH}$ values from 13.6 to $10)$, a cathodic process was identified at potentials below $0.6 \mathrm{~V}$ vs. RHE (i.e., at about $-0.3 \mathrm{Vvs}$. $\mathrm{Ag} / \mathrm{AgCl}$ ) that was related to an unidentified base active surface functionality [26]. This is consistent with the observed mass loss being due to a reduction process associated 
(a)

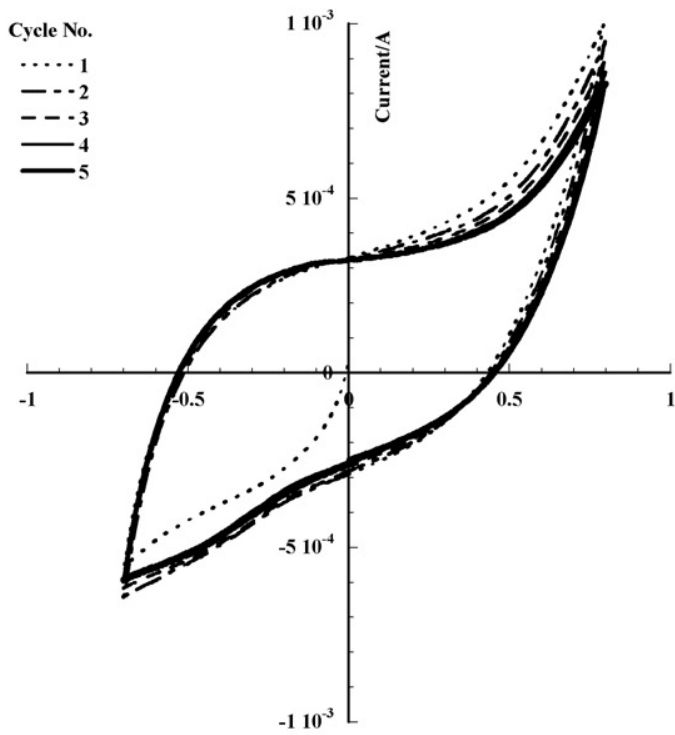

(b)

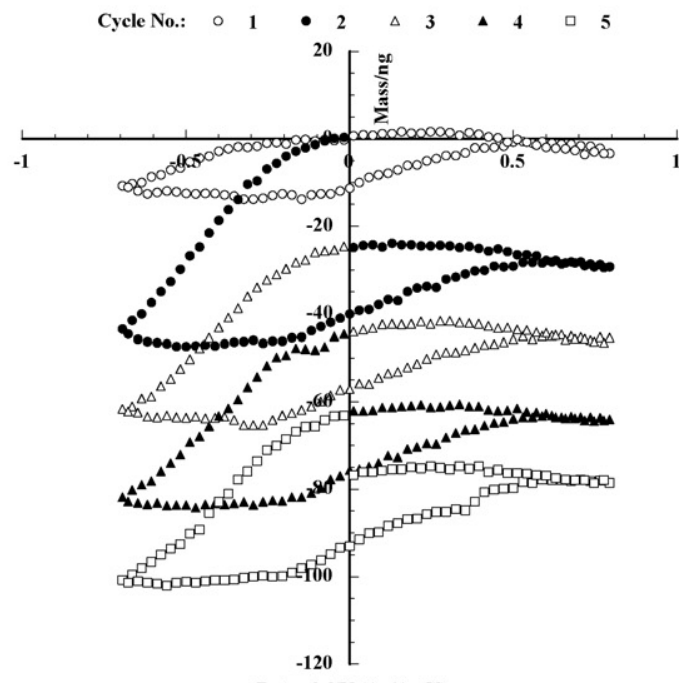

(c)

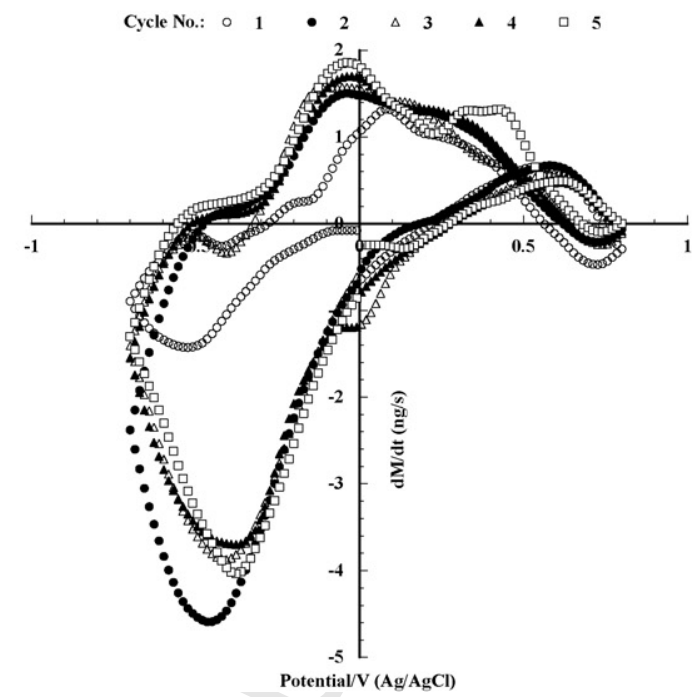

Fig. 2. (a) Voltammogram; (b) electrode mass behavior; and (c) massogram $(\mathrm{d} M / \mathrm{d} t$ vs. E) of the carbon electrode at a solution $\mathrm{pH}$ of 12 at $50 \mathrm{mV} / \mathrm{s}$ in the $\mathrm{NaCl}$ electrolyte Aor five voltammetric cycles with no arsenic in solution. with carbon-oxygen surface groups, most probably formed on the carbon surface during the anodic sweep.

The corresponding massogram for the five consecutive cycles is presented in Fig. 2c. In this figure, the large, broad mass loss peak during the cathodic sweep is clearly evident with a maximum at approximately $-0.4 \mathrm{~V}$, as well as the much broader, but smaller mass gain peak centered at approximately $\bar{\wedge} 0.1 \mathrm{~V}$ during the anodic sweep.

Under anodic conditions in alkaline solution, carbon oxidation can occur via adsorption of hydroxide and oxidation of carbon in a fashion analogous to what occurs on Pt, as discussed above; i.e.,

$\mathrm{C}()+2 \mathrm{OH}^{-} \rightarrow \mathrm{C}(\mathrm{O})+\mathrm{H}_{2} \mathrm{O}+2 \mathrm{e}$,

or

$2 \mathrm{C}()+3 \mathrm{OH}^{-} \rightarrow \mathrm{C}\left(\mathrm{O}_{2}\right)+\mathrm{C}(\mathrm{H})+\mathrm{H}_{2} \mathrm{O}+3 e$,

where $\mathrm{C}()$ is a reactive carbon site, and $\mathrm{C}(\mathrm{O})$ and $\mathrm{C}\left(\mathrm{O}_{2}\right)$ are carbon-oxygen surface complexes. Under alkaline conditions, these can be various types of complexes like semiquinones, carboxyls, phenols, esters, etc. Therefore, as used here, $\mathrm{C}(\mathrm{O})$ and $\mathrm{C}\left(\mathrm{O}_{2}\right)$ are simply intended to be representative of the various types of $\mathrm{CO}$ and $\mathrm{CO}_{2}$-producing carbon-oxygen surface complexes that may participate in the carbon redox processes. The broad mass gain peak in Fig. 2c during the anodic sweep is attributed to oxidation processes like reactions (10 and 11) that produce carbon-oxygen surface complexes.

Under cathodic conditions in alkaline solution, carbon-oxygen surface complexes can also be reduced according to reactions like:

$$
\begin{aligned}
& \mathrm{C}(\mathrm{O})+2 \mathrm{H}_{2} \mathrm{O}+2 \mathrm{e} \\
& \rightarrow \mathrm{CO}+2 \mathrm{C}(\mathrm{H})+2 \mathrm{OH}^{-}, \text {or }_{\perp} \mathrm{CO}+2 \mathrm{C}()+\mathrm{H}_{2}+2 \mathrm{OH}^{-} \\
& \mathrm{C}\left(\mathrm{O}_{2}\right)+3 \mathrm{H}_{2} \mathrm{O}+3 \mathrm{e} \\
& \rightarrow \mathrm{CO}_{2}+3 \mathrm{C}(\mathrm{H})+3 \mathrm{OH}_{\Lambda}^{-}, \text {or }_{\perp} \mathrm{CO}_{2}+\mathrm{H}_{2}+\mathrm{C}()+\mathrm{C}(\mathrm{H})+2 \mathrm{OH}^{-}
\end{aligned}
$$

to produce gaseous oxides of carbon, and, possibly, $\mathrm{H}_{2}$. These are electrogasification steps that cause mass loss from the carbon electrode as $\mathrm{CO}$ and $\mathrm{CO}_{2}$, as well as create additional carbon active sites from the broken bonds created when the solid carbon atom leaves the surface as a carbon oxide.

Addition of the two half-cell reactions (10) and (12), and (11) and (13) yield:

$$
\begin{aligned}
& \mathrm{C}()+\mathrm{H}_{2} \mathrm{O} \rightarrow \mathrm{CO}+2 \mathrm{C}(\mathrm{H}), \operatorname{\theta rCO}+\mathrm{H}_{2} \\
& \mathrm{C}()+2 \mathrm{H}_{2} \mathrm{O} \rightarrow \mathrm{CO}_{2}+4 \mathrm{C}(\mathrm{H}), \operatorname{\theta rCO} \mathrm{CQ}_{2}+2 \mathrm{H}_{2}
\end{aligned}
$$

which are electrochemical analogs in alkaline solution of the wellknown thermal steam gasification reaction.

Electrochemical carbon gasification, or electrogasification, also sometimes referred to by the more generic term of "carbon corrosion," which includes oxidation, has been reported by a number of authors in various electrochemical contexts [27-29]. Such redox cycles involving net carbon loss account for at least some of the mass loss observed during the cathodic sweep, as well as the mass increase during the anodic sweep by forming carbon-oxygen surface complexes. Electrogasification is the background against which the arsenic redox reactions occur on the $\mathrm{CE}$, as discussed below.

Although the gasification products are $\mathrm{CO}, \mathrm{CO}_{2}$, and $\mathrm{H}_{2}$, it is important to note that no gas bubbles were ever observed on the surface or in the vicinity of the electrode. This is understandable in terms of the very small amounts of gas generated per cycle. For example, assuming an upper limit of gas generation of about $18 \mathrm{ng}$ of $\mathrm{CO}$, this is about $0.6 \mathrm{nmol}$, which is a total gas volume of $0.015 \mu \mathrm{l}$ per cycle. This entire amount would form one gas bubble $300 \mu \mathrm{m}$ 
in diameter. However, since gas generation is distributed over the entire electrode surface, it is much more likely that the generated gases dissolve in solution. Under these conditions, the saturation level of dissolved CO in water in contact with CO gas is $990 \mathrm{nmol} / \mathrm{ml}$ [30], which far exceeds the electrogasification generation capacity in the present experiments. $\mathrm{H}_{2}$ bubbles would not be observed either for the same reason since the value of the Henry's law constant for $\mathrm{H}_{2}$ is similar to that for $\mathrm{CO}$ [30]. $\mathrm{CO}_{2}$ bubbles would not be observed either, for similar reasons, especially since $\mathrm{CO}_{2}$ is even more soluble in water than $\mathrm{CO}$ (i.e., the Henry's law constant for $\mathrm{CO}_{2}$ in water is two orders of magnitude greater than that for CO [30]). Consequently, the cathodic mass loss peak in Fig. 2c is attributed to electrogasification processes like reactions (12 and 13 ).

The formation of $\mathrm{C}(\mathrm{H})$ complexes on the carbon surface is also likely. Indeed, hydrogen chemisorption on carbon active sites has recently been detected in electrochemical experiments by in situ Raman spectroscopy [31]. It is also well known that gas phase hydrogen dissociatively chemisorbs on carbon active sites, and can also recombine to release $\mathrm{H}_{2}$ [32-35]. In alkaline solution, active carbon sites can also be generated anodically from $\mathrm{C}(\mathrm{H})$ sites via $\mathrm{OH}^{-}$adsorption and hydrogen abstraction:

$\mathrm{C}(\mathrm{H})+\mathrm{OH}^{-} \rightarrow \mathrm{C}()+\mathrm{H}_{2} \mathrm{O}+\mathrm{e}$

The $\mathrm{C}\left(\right.$ ) sites could then be further oxidized to $\mathrm{C}(\mathrm{O})$ or $\mathrm{C}\left(\mathrm{O}_{2}\right)$. However, since more than one active site can be produced for every cathodic gasification step (exactly how many depend on the nature of the oxygen surface complex decomposed, as well as the nature of the carbon (for example, whether it is ordered or disordered), the important point is that carbon electrogasification produces additional carbon sites that are available for arsenic redox as well.

\subsection{EQCM response of the CE in arsenic-containing electrolyte}

In Fig. 3a are presented the steady CV data for the CE as a function of arsenic concentration in the electrolyte solution. A comparison of Figs. 2a and 3a shows considerable changes with increasing arsenic concentration. In particular, the current decreases appreciably over the entire cycle. This decrease of the double layer charge may be at least partially attributable to the effect of substitution of the much larger $\mathrm{As}(\mathrm{V})$ anions $\left(\mathrm{AsO}_{4}{ }^{3} \mathrm{\Lambda}\right)$ for chlorine ions, even though they are less concentrated.

In Fig. 3b are presented the corresponding mass data for the CE. Qualitatively, these data are remarkably similar to those for the bare Pt electrode in arsenic solutions in Fig. 1b, except that the mass variations are considerably larger (attributed to the larger number of active sites in the CE than on the bare Pt electrode). The similarity is due to the fact that the redox mechanisms for the Pt and $\mathrm{C}($ ) sites are mechanistically similar. However, as noted previously, the arsenic-free data on the bare Pt electrode in Fig. 1b show no net mass change upon cycling, whereas the corresponding data for the CE electrode in Fig. 2b exhibit a relatively large net mass loss on the order of $18 \mathrm{ng}$ per cycle due to carbon electrogasification. But, the net electrode mass data for the arsenic-containing solutions in Fig. 3b all still show relatively small net mass losses per cycle, just as in Fig. 2p.

Even though arsenic and oxygen may compete for similar active carbon sites in the CE electrode, even at 100 ppm the arsenic concentration is still an order of magnitude less than that of $\mathrm{OH}^{-}$, and thus there should be relatively little difference in the carbon electrogasification rate in the presence of arsenic. Consequently, the large net mass loss of the CE due to carbon electrogasification at the end of the cathodic sweep "masks" the cathodic mass gain due to arsenic in peak C. Instead of a mass loss, on the CE electrode there is clearly a significant mass gain due to arsenic reduction over successive cycles for all the arsenic concentrations. It is also noted that the behavior of the mass loss in peak $A$ is very similar (a)

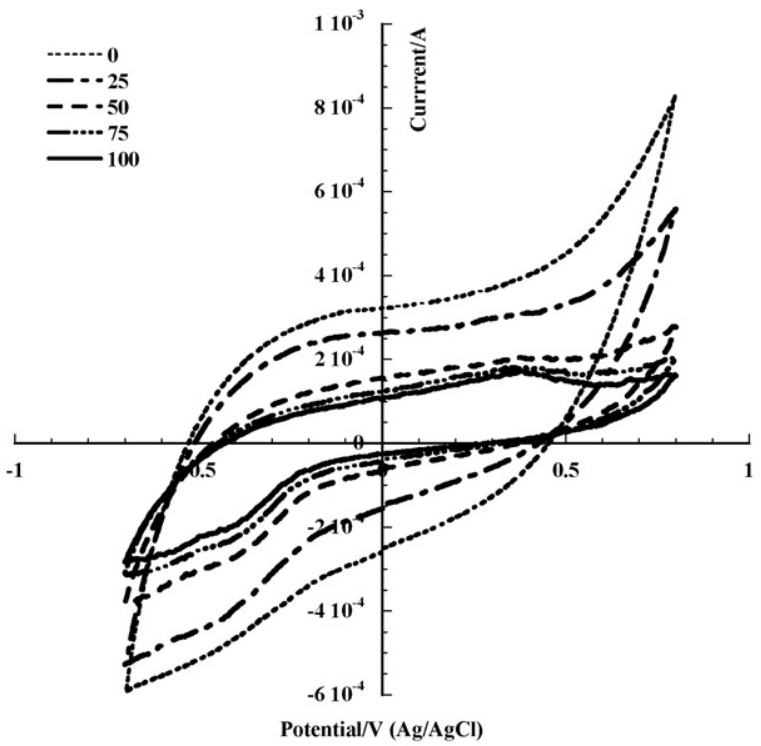

(b)

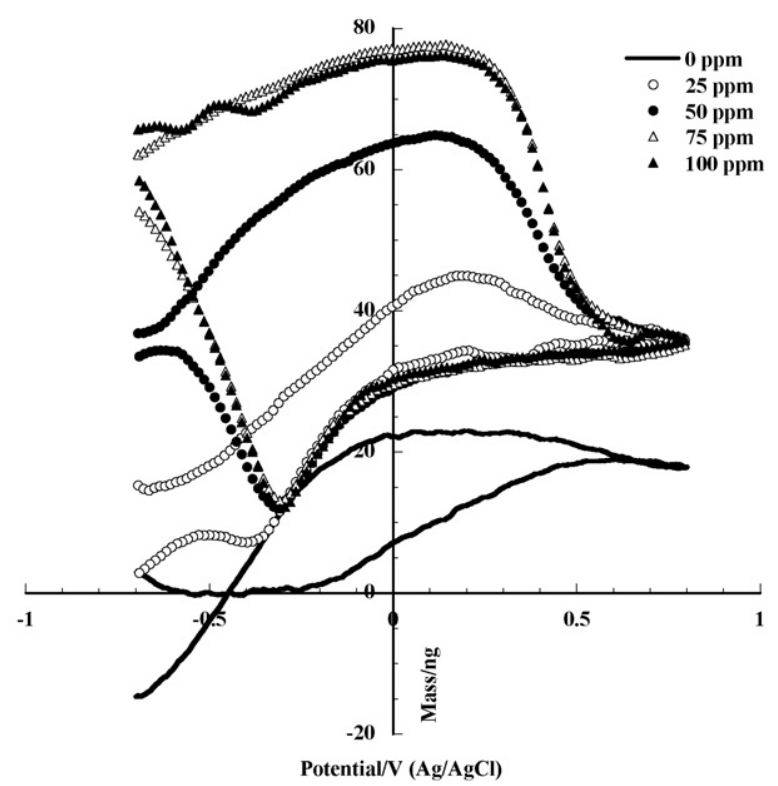

Fig. 3. (a) Voltammogram; and (b) mass behavior of the carbon electrode at a solution $\mathrm{pH}$ of 12 at $50 \mathrm{mV} / \mathrm{s}$ in $\mathrm{NaCl}$ electrolyte as a function of arsenic concentration. The data all correspond to the fifth voltammetric cycle beginning with a positive potential sweep from $0 \mathrm{~V}$, except for the anodic sweep portion from -0.7 to $0 \mathrm{~V}$, which is the end of the fourth cycle.

to what was found on the bare Pt electrode. That is, following the peak there is still a relatively large residual mass of arsenic left on the electrode which gradually decreases with decreasing potential during the cathodic sweep. This suggests a similar arsenic oxidation process occurring in peak $\mathrm{A}$ as that for the bare Pt electrode; that is, oxidation of surface $\mathrm{AsO}_{1.5}$ and $\mathrm{As}(\mathrm{III})$ from solution. However, a similar analysis cannot be performed for the CE as for the Pt electrode because the faradaic current data are obscured by the relatively large capacitative current.

The behavior of the total mass of the CE for five successive cycles as a function of arsenic concentration is shown in Fig. 4a. Correcting these data for the effect of carbon electrogasification by subtracting the CE mass loss data in the absence of arsenic yields Fig. 4b. As expected from the preceding discussion, the net mass loss per cycle observed in Fig. 4a "masks" the mass gain due to arsenic reduction on additional active sites created by carbon electrogasification during the cyclic process. After the first cycle, the net 

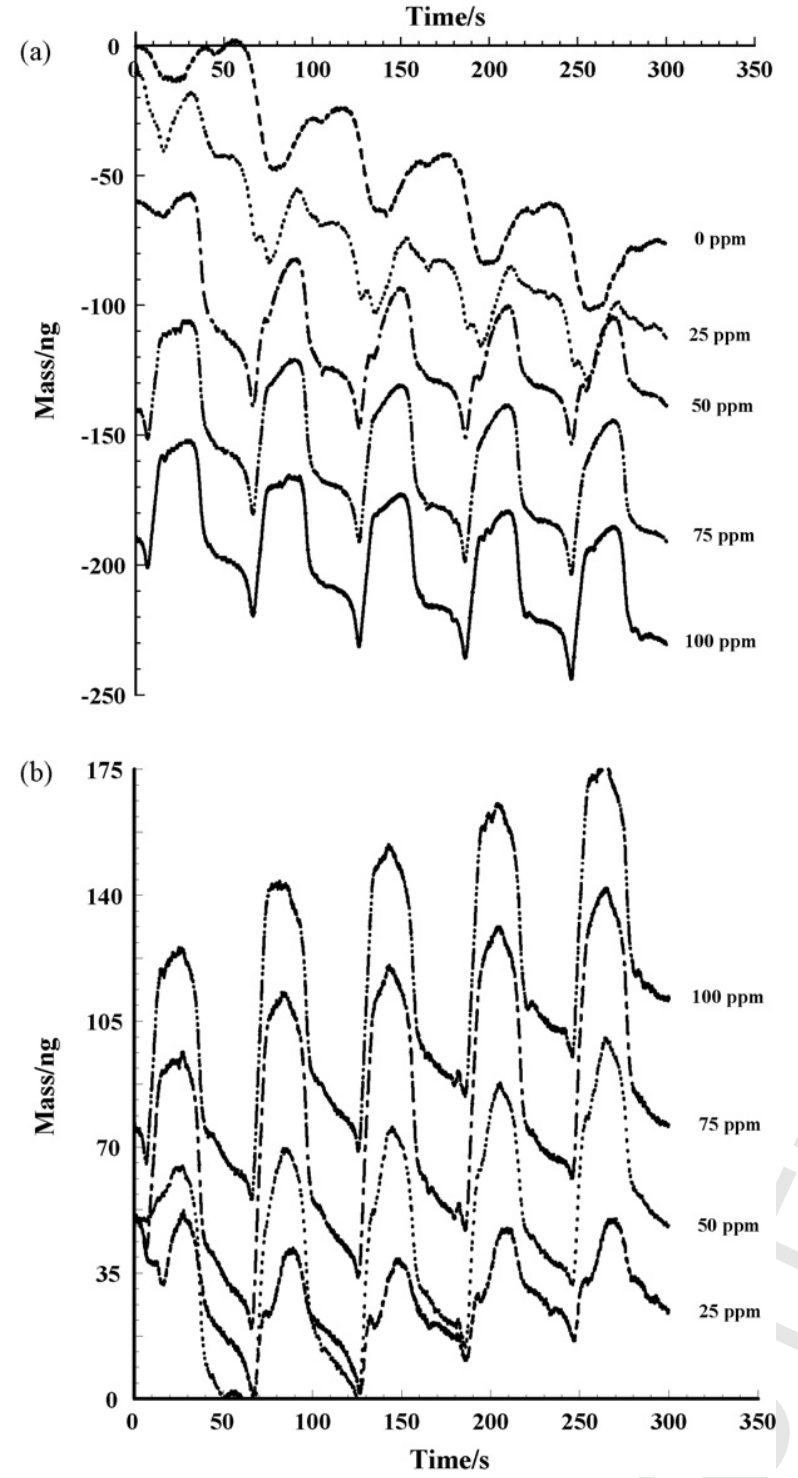

Fig. 4. (a) Total mass behavior of the carbon electrode, and (b) "corrected" mass behavior due just to arsenic at a solution $\mathrm{pH}$ of 12 at $50 \mathrm{mV} / \mathrm{s}$ in the $\mathrm{NaCl}$ electrolyte for five CV cycles as a function of arsenic concentration.

mass loss observed in Fig. 4a and the arsenic mass gain in Fig. 4b become relatively linear with cycle or time. From Fig. 4a, the electrogasification rate in the absence of arsenic is about $18 \mathrm{ng} /$ cycle. For a $0.25 \mathrm{mg}$ carbon electrode, this corresponds to a gasification rate of $72 \mu \mathrm{g} / \mathrm{g} /$ cycle, or about $72 \mu \mathrm{g} / \mathrm{g} / \mathrm{min}$. From Fig. 4b, the net mass gain per cycle for the $100 \mathrm{ppm}$ arsenic solution data is about $18-7=11 \mathrm{ng} /$ cycle. Assuming that the mass gain is mostly as $\mathrm{AsO}_{1.5}$, this suggests that the increase in net cathodic arsenic removal is about $0.11 \mathrm{nmol} / \mathrm{cycle}$, or, for an estimated $0.25 \mathrm{mg}$ of carbon in the CE, $444 \mathrm{nmol} \mathrm{As/gC/cycle,} \mathrm{or} 444 \mathrm{nmol} \mathrm{As/gC/min.}$

The corresponding massograms for the $100 \mathrm{ppm}$ arsenic solution on the CE for five cycles in Fig. 4 are presented in Fig. 5. As shown, they appear qualitatively similar to those in Fig. 1c for the bare Pt electrode in the presence of arsenic. However, peaks $A$ and $C$ are considerably larger, and peak $\mathrm{B}$, although comparable, is slightly smaller. The maximum of the cathodic mass loss peak B is located at about $-0.2 \mathrm{~V}$, rather than about $-0.4 \mathrm{~V}$ as in Fig. $1 \mathrm{c}$, and the cathodic mass gain peak $C$ is larger and broader and located at about $-0.5 \mathrm{~V}$. However, the arsenic oxidation peak $\mathrm{A}$, although larger, is still located at about $+0.4 \mathrm{~V}$. The differences in peaks $\mathrm{B}$ are consis-

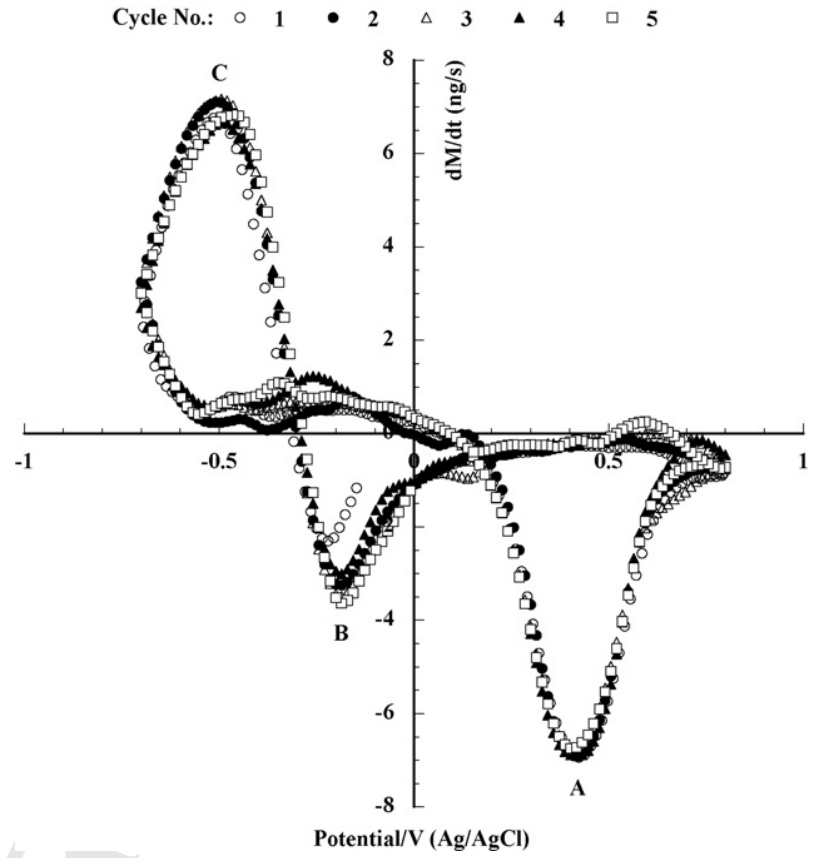

Fig. 5. Massogram $(\mathrm{d} M / \mathrm{d} t$ vs. E) of the carbon electrode mass behavior at a solution $\mathrm{pH}$ of 12 at $50 \mathrm{mV} / \mathrm{s}$ with $10 \mathrm{Oppm}$ arsenic in the $\mathrm{NaCl}$ electrolyte solution for five $\mathrm{CV}$ cycles.

tent with the difference in electrode materials. That is, peak B in Fig. 5 most probably involves reduction of carbon-oxygen surface complexes, as well as oxy-arsenic surface complexes. The oxidation of carbon sites evident in Fig. 2c appears to be suppressed in Fig. 5, most probably as a result of competition with arsenic.

The large cathodic mass gain peak appears to be analogous to, although much greater than that observed on the bare Pt electrode (peak C). This is attributed primarily to the uptake of $\mathrm{As}(\mathrm{V})$ on carbon active sites, some of which are created by electrogasification, followed by reduction to $\mathrm{As}(0)$ and $\mathrm{AsO}_{1.5}$, analogous to the overall stoichiometry of the reactions on Pt; i.e.,

$\mathrm{C}()+\mathrm{AsO}_{4}{ }^{3} \bar{\Lambda}+4 \mathrm{H}_{2} \mathrm{O}+5 \mathrm{e} \rightarrow \mathrm{C}(\mathrm{As}(0))+8 \mathrm{OH} \bar{\wedge}$,

followed by reaction (9) to produce $\mathrm{As}_{2 \mathrm{n}} \mathrm{O}_{3 n}$. surface complexes. Correspondingly, the large mass loss peak at positive potentials (peak $\mathrm{A}$ ) is attributed to the oxidation of $\mathrm{As}(\mathrm{III})$, both from $\mathrm{As}_{2 \mathrm{n}} \mathrm{O}_{3 \mathrm{n}}$ surface complex species, as well as from solution, and their desorption as $\mathrm{As}(\mathrm{V})$.

\section{Conclusions}

The interactions of arsenic species with platinum and porous carbon electrodes have been investigated and compared using EQCM and cyclic voltammetry in alkaline solutions. In the case of the bare Pt electrode, the processes associated with the adsorption/desorption of oxygen and hydrogen can be well differentiated with the EQCM. In the presence of arsenic, reduction/deposition of As, as well as electrocatalyzed oxidation/desorption by Pt can be distinguished with the EQCM. These features are all shifted to more negative potentials than in acidic media, in agreement with the $\mathrm{pH}$ dependence of the arsenic redox reactions. The EQCM results reveal that the redox of arsenic on the porous carbon electrode is mechanistically similar to that on the bare Pt electrode.

For the porous carbon electrode, a continual mass loss was always observed during potential cycling, with or without arsenic in the solution. This was attributed to carbon electrogasification. The proposed mechanism includes the anodic formation of carbon-oxygen surface complexes, and their cathodic reduction, with 
the overall reaction being analogous to thermal steam gasification of carbon. The apparent mass loss per cycle was observed to decrease with increasing arsenic concentration. This was attributed to a net increase in adsorbed arsenic per cycle that increased with arsenic concentration, offsetting the carbon mass loss. This was attributed to additional carbon adsorption sites involved in arsenic species interactions, created by electrogasification, thereby augmenting the net uptake of arsenic per cycle.

It is demonstrated that EQCM is a very useful technique for distinguishing arsenic species interactions with carbon electrodes. The latter is difficult to accomplish with just classical cyclic voltammetry due to the large contribution of the double layer for most carbon materials. Consequently, EQCM techniques may also prove to be effective for investigating the redox/adsorption/desorption characteristics of other species with carbon materials as well.

\section{Acknowledgements}

This work was partially supported by grant number 5 P42 ES013660 from the U.S. National Institute of Environmental Health Sciences (NIEHS), NIH, and by the Generalitat Valenciana (RED ARVIV/2007/076) and Ministerio de Educación y Ciencia (Project CTQ2006-08958/PPQ). The authors also wish to acknowledge the following: E. Morallon to the Generalitat Valenciana for a travel grant (BEST/2007/038); J.M. Calo for support from the Programa de Ayuda para Investigadores Senior, 2006, from the Universidad de Alicante; and D. Cazorla-Amorós for a travel grant (PR2007-177) from the MEC (Spain).

\section{References}

[1] N.N. Greeenwood, A. Earnshaw, Chemistry of the Elements, 2nd ed., Butterworth-Heinemann, 1997.

[2] K. Jain, I. Ali, Wat. Res. 34 (2000) 4304.

[3] X. Dai, R.G. Compton, Analyst 131 (2006) 516

[4] G. Dugo, L. La Pera, V. Lo Turco, G. Di Bella, Chemosphere 61 (2005) 1093.
[5] J.R. Parga, D.L. Cocke, J.L. Valenzuela, J.A. Gomes, M. Kesmez, G. Irwin, H. Moreno, M. Weir, J. Hazard. Mat. B124 (2005) 247.

[6] M.N. Amin, S. Kaneco, T. Kitagawa, A. Begum, H. Katsumata, T. Suzuki, K. Ohta, Ind. Eng. Chem. Res. 45 (2006) 8105.

[7] Y. Gao, J.M. Calo, G. Hradil, P. Yao, July 2006. Paper No. SA477, presented at Carbon2006, Aberdeen, Scotland.

[8] L.R. Radovic, C. Moreno-Castilla, J. Rivera-Utrilla, in: L.R. Radovic (Ed.), Chemistry and Physics of Carbon. 2001, vol. 27, Marcel Dekker, New York, 2001, p. 227.

[9] J.S. Noh, J.A. Schwarz, Carbon 28 (1990) 675.

[10] CHemical Equilibria in AQuatic Systems (CHEAQS) Pro program, Wilko Verweij, 2008, The Netherlands.(http://www.home.tiscali.nl/cheaqs/).

[11] D.A. Buttry, M.D. Ward, Chem. Rev. 92 (1992) 1355.

[12] M. Urbakh, L. Daikhin, Langmuir 10 (1994) 2836.

[13] L. Daikhin, M. Urbakh, Farady Discuss. 107 (1997) 27.

[14] G.A. Snook, A.M. Bond, S. Fletcher, J. Electroanal. Chem. 526 (2002) 1.

[15] E. Morallon, J.L. Vazquez, A. Aldaz, J. Electroanal. Chem. 288 (1990) 217

[16] J.M. Perez, E. Muñoz, E. Morallón, F. Cases, J.L. Vazquez, A. Aldaz, J. Electroanal. Chem. 368 (1994) 285.

[17] T.D. Cabelka, D.S. Austin, D.C. Johnson, J. Electrochem. Soc. 131 (1984) 1595.

[18] D.G. Williams, D.C. Johnson, Anal. Chem. 64 (1992) 1785.

[19] M. Shibata, T. Kobayashi, N. Furuya, J. Electroanal. Chem. 436 (1997) 103.

[20] F. Brusciotti, P. Duby, Electrochim. Acta 52 (2007) 6644.

[21] D.G. Brookins, Eh-pH Diagrams for Geochemistry, Springer-Verlag, Berlin, 1988.

[22] J.F. Ferguson, J. Gavis, Water Res. 6 (1972) 1259.

[23] P. Díaz-Arista, G. Trejo, Surf. Coat. Tech. 201 (2006) 3359

[24] S. Kologo, M. Eyraud, L. Bonou, F. Vacandio, Y. Massiani, Electrochim. Acta 52 (2007) 3105

[25] A. Méndez, P. Díaz-Arista, L. Salgado, Y. Meas, G. Trejo, Int. J. Electrochem. Sci. 3 (2008) 918

[26] H.A. Andreas, B.E. Conway, Electrochim. Acta 51 (2006) 6510

[27] D.A. Stevens, J.R. Dahn, Carbon 43 (2005) 179.

[28] S. Maass, F. Finsterwalder, G. Frank, R. Hartmann, C. Merten, J. Power Sources 176 (2008) 444.

[29] C.U. Pittman, W. Jiang, Z.R. Yue, C.A. Leon y Leon, Carbon 37 (1999) 85

[30] D.R. Lide, H.P.R. Frederikse (Eds.), CRC Handbook of Chemistry and Physics, 76th Ad., CRC Press, Inc, Boca Raton, FL, 1995.

[31] M.J. Bleda-Martínez, J.M. Pérez, A. Linares-Solano, E. Morallón, D. CazorlaAmorós, Carbon 46 (2008) 1053.

[32] D.L. Biederman, A.J. Miles, F.J. Vastola, P.L. Walker Jr., Carbon 14 (1976) 351

[33] K.J. Hüttinger, Carbon 23 (1988) 79.

[34] M.H. Treptau, D.J. Miller, Carbon 29 (1991) 531.

[35] J.M. Calo, D. Cazorla-Amorós, A. Linares-Solano, M.C. Roman-Martínez, C. Salinas-Martínez de Lecea, Carbon 35 (1997) 543. 